\title{
Determinants of Gratuity Size in the Czech Republic: Evidence from Four Inexpensive Restaurants in Brno ${ }^{1}$
}

\author{
Michal Kvasnička, Monika Szalaiová ${ }^{2}$
}

\begin{abstract}
The paper presents the results of the first study exploring what factors influence tipping in restaurants in the Czech Republic. It shows that the tipping norm evolved here into a form that has some features similar to the tipping norms known in the USA, Canada, and Israel, but there are also striking differences. As in the three countries, the gratuity increases with the bill size but the gratuity as percentage of the bill is much lower here. The bill size explains here a lower part of the gratuity variability too. Also, the service quality results in customers being more generous with their tips, and though the increase in gratuity seems to be small, it rises with a group size. Strikingly, the regular patrons tip significantly less in the Czech Republic and they stiff more often. This supports the hypothesis that the relationship between the customer frequency and the gratuity size is an artifact of a missing variable, and the regular patrons tip differently because they belong to a different social group than occasional customers. Also, the customers paying by card stiff more often here and the interaction between the amount on the bill and use of payment card is statistically insignificant. The group size lowers the percentage gratuity, which supports the diffusion of the responsibility hypothesis. There are differences between genders: Male customers leave bigger tips than female customers, and female waitresses earn more than their male colleagues. The time spent at the table, consumption of alcoholic beverage, and smoking do not change the gratuity size but it may be affected by the weather conditions. The customers tip less and stiff more often when they order a lunch special. They round the total expenditures, not the gratuities, which creates the magnitude effect.
\end{abstract}

Key words: restaurant tipping, the Czech Republic

JEL Classification: L83, D12

\section{Introduction}

Tipping has aroused an interest of many researchers for several reasons. First, it is quantitatively important in many countries, especially in the USA. Azar (2007a) claims that the total amount of gratuity is around 27 billion US dollars a year in the US

\footnotetext{
${ }^{1}$ The paper has been created as a part of specific research no. MUNI/A/1203/2014 at the Masaryk University.

${ }^{2}$ Masaryk University, Faculty of Economics and Administration, Lipová 41a, 60200 Brno, the Czech Republic, michal.kvasnicka@econ.muni.cz
} 
restaurants. Lynn (2006) claims that net incomes of US waitresses and waiters consist almost entirely of gratuities because their wages are retained as tax withholding. Second, tipping is a puzzling behavior, at least for economists. A self-interested agent should not tip unless she repeatedly interacts with the same waiter because tips are paid after the service is delivered and are not legally enforceable. Yet most people tip even in restaurants they do not plan to revisit. This seems to suggest that tipping is influenced not only by economic considerations but also by social norms and psychological factors. For these reasons, tipping has been widely studied not only by economists but also by psychologists, sociologists, demographers, and anthropologists. Third, the particular features of the social norm of tipping have important managerial consequences. For instance, if customers vary the amount tipped based on the quality of service delivered by waiters and waitresses, tipping can substitute explicit managerial supervision over the employees, which can save restaurants' cost. On the other hand, if sensitivity of gratuity on the service quality is low, the supervision is needed and the tipping can be replaced either with a higher price or with an automatic service fee (such as is charged in many European countries). Fourth, tipping has also important consequences for the economic policy and social welfare, see e.g. Lynn (2006).

Although tipping is an interesting, important, and widely studied phenomenon, empirical studies have focused on only few countries so far: the USA, Canada, and Israel. In particular, we are not aware of any study of the tipping behavior in the Czech Republic. This paper attempts to cover this gap. Its goal is to explore how much customers tip in Czech restaurants, what determines the gratuity size, and how the Czech tipping norm differs from those known from the USA, Canada, and Israel. The comparison of the tipping norms among the countries that have undergone a different development can provide us with some insight whether the tipping norm is a result of economic and psychological forces common to the whole mankind, or whether it is a peculiar product of a particular time and place. The Czech Republic is suitable for this kind of research because it underwent a completely different history from the three countries mentioned above, and tipping probably has a different origin here-and yet the employees are tipped on voluntary basis in many occupations in the Czech Republic. This study also provides a necessary basis for further research of the tipping behavior in the Czech Republic.

\section{Literature Review}

Since literature on tipping is immense and there already are two great reviews (Azar, 2007a, and Lynn, 2006), we will discuss here only those results of the recent empirical studies on the determinants of the gratuity size in restaurants that are relevant for our study. Most of these results were obtained in the USA, the rest in Canada and Israel. The data were collected by various methods, usually by exit surveys (the customers were interviewed by researchers when they were leaving restaurants), hypothetical surveys (selected people were asked how much they would tip in prescribed situations), or observation in real situations or in field experiments (the data were partially collected by cooperating waiters and partially by researchers). A typical study utilized slightly more than one hundred observations but there were some more extensive studies, too. 
The bill to be paid is the most important determinant of gratuity size. Lynn (2006) claims that it explains on average $69 \%$ of the within-restaurant variability of the dollars gratuity size. This is hardly surprising since there is a widely known and accepted social norm to tip a certain percentage of the bill in all these three countries. For instance, etiquette guides suggest tipping 15 to $20 \%$ of the bill size in the USA (Lynn, 2006). The empirical studies support this norm: Conlin, Lynn, and O'Donoghue (2003) reported the average gratuity to be $17.5 \%$ of the bill, Lynn and Latané (1984) about $15.5 \%$, Bodvarsson and Gibson (1997) $15 \%$ (but it differed among restaurants), Bodvarsson, Luksetich, and McDermott (2003) $14.3 \%$, Lynn, Jabbour, and Kim (2012) $10-16 \%$, and Harris (1995) about $14 \%$. However, some researchers found lower gratuities. For instance, Bodvarsson and Gibson (1994) report only $11 \%$. Moreover, the social norm holds true only on average and there are significant differences between individuals. Rogelberg et al. (1999) explored individual tipping behavior by the means of policy capturing and found out that one third of the restaurant customers tip less than $10 \%, 61 \%$ of the customers tip from 10 to $15 \%$, and about one tenth of the customers tip more than $15 \%$. The tipping norms are slightly lower both in Canada, see e.g. Bodvarsson and Gibson (1999), and in Israel, see Azar (2010a).

Several studies, e.g. Lynn and Grassman (1990), Green, Myerson, and Schneider (2003), Conlin, Lynn, and O’Donoghue (2003), Lynn and Sturman (2003), and Azar (2010b) found out that there is a positive intercept when the dollar gratuity is regressed on the bill size, and hence the gratuity as a percentage of the bill size decreases with the rise of the bill size. This is called the magnitude effect. This effect means that even though the average percentage gratuity is about $15 \%$ of the bill size, the marginal effect of the bill size increase is smaller. There are several possible explanations of this phenomenon: 1) customers tend to tip some minimal fixed amount if the bill is small; 2) customers tip a fixed amount above the usual percentage as a reward for the waiters that they appeared at all; 3) people round their gratuity up to whole dollars (and the average percentage value of the rounding decreases as the bill size increases); or 4) some people tip flat, i.e. they tip an amount independent of the size of the bill, see Lynn (2006) and Azar (2007a). Lynn and Sturman (2003) claim that presence of the flat tippers is the most likely explanation, at least in the USA. Unlike the other explanations, this is also consistent with the finding that the dollar gratuity increases with the size of the bill and the bill squared (Lynn, Jabbour, and Kim, 2012). However, Lynn, Jabbour, and Kim (2012) found that a great amount of tips is rounded up to whole dollars (they claim that people think about the gratuity in dollar terms, not as a percentage of the bill size), which provides some support to the rounding hypothesis.

The relationship between the gratuity size and the bill size can be modified by many factors. Patronage frequency is one of the most important ones. A simple economic theory predicts that a self-interested agent should not tip at all unless his or her interaction with the waiter/waitress is repeated. Several theoretical models of the social norm of tipping predict that the size of the tip and or its sensitivity to the service quality should be higher for regular patrons than for one-time customers, see e.g. Azar (2007b). However, empirical results are mixed. Several studies found out that regular patrons tip more than the one-time customers, see Lynn and Grassman (1990), Lynn and McCall (2000), Conlin, Lynn, and O'Donoghue (2003), Bodvarsson and Gibson (1994), Azar (2007b), and Azar (2010b). On the other hand, Bodvarsson and Gibson (1997) found the 
relationship statistically significant only in two of seven restaurants, and even there it was small. Hypothetical surveys found no relationship between patronage frequency and the gratuity size (Kahneman, Knetsch, and Thaler, 1986, and Azar, 2010a). A possible explanation is that the patronage frequency does not significantly affect the tipping behavior but serves as a proxy for a missing variable, most likely for the unobserved income which is correlated with the gratuity size (Azar 2010a). Nonetheless, Lynn (2006) thinks the relationship is genuine.

Service quality is the second most important modifier of the relationship between the gratuity size and the bill size. The service quality is rated by the customers on some scale, e.g. from one to five ${ }^{3}$. Either it is rated as a whole, or it is split into several factors, such as friendliness, promptness, attentiveness, appearance, and knowledge of the menu. Theoretical models of the tipping norm predict that customers should tip more when the service quality is better, and that the regular patrons should be more sensitive to the service quality than occasional customers, see e.g. Azar (2007b). Empirical results are mixed again. The hypothetical surveys found out that customers indeed tip significantly more for a better service - the regression parameters were statistically significant and the difference in the dollar tips was economically significant and able to motivate the waiting staff to provide a good service, see Bodvarsson and Gibson (1999) and Azar (2010b). However, the exit surveys found a very weak or non-existent relationship between the service quality and the gratuity size. Lynn and Latané (1984) found no relation. Bodvarsson and Gibson (1997) found a positive relationship in five out of seven restaurants but a negative one in the two other restaurants; the relationship was positive on average but very weak over all seven restaurants. Lynn and McCall (2000) found a positive relationship but it was so weak that they doubted whether waiters and waitresses could really see it in their earnings. Lynn (2003) found very a weak relationship, and so did Azar (2009). Bodvarsson and Gibson (1994) offer an explanation of the discrepancy between the results of the hypothetical and exit surveys. They claim that the relationship between the gratuity size and the service quality cannot be estimated from the exit survey data because the variability of the quality measures is too small (on the quality scale of one to five, most customers rank the quality as four or five). This is because of a selection bias: only well-performing waiting staff can survive in the industry where gratuity is their major source of income. Azar (2007a) offers two different explanations for the discrepancy: 1) The customers want to tip based on the service quality but they succumb to the pressure of the tipping norm at the restaurant. 2) The service quality is endogenous-the waiting staff can guess how much a particular customer would tip and adjust their effort accordingly. The later explanation is consistent with findings of Bodvarsson and Gibson (1994) who corrected for the service quality endogeneity by estimating the relationship between the gratuity size and its determinants using a TSLS model. They found a strong relationship between the gratuity size and the service quality in their exit survey data. Yet another explanation may be that there are differences among customers. Rogelberg et al. (1999) found out

\footnotetext{
${ }^{3}$ Lynn (2003) shows the precise form of the scale is not important and different methods of quality assessment produce the same results.
} 
that some customers tip more for a better service while others do not. Whatever the relationship between the gratuity size and the service quality may be, the interactions between the service quality and the patronage frequency is statistically insignificant (Azar 2010b), i.e. contrary to the economic theory, the regular patrons do not tip more sensitively to the service quality than the one-time customers.

Quantity of services provided by the waiting staff may by another important determinant of the gratuity size. (The bill size may only be a proxy for the service quantity.) The empirical results are mixed again. Bodvarsson and Gibson (1994) found a statistically significant relationship between the gratuity size and the service quantity measured as the number of items (meals, drinks, desserts, etc.) that a waiter brought to a table even when they controlled for the bill size. However, Conlin, Lynn, and O'Donoghue (2003) and Lynn and Grassman (1990) found no significant relationship. Lynn, Jabbour, and Kim (2012) found out that the gratuity size rises with the time the customers spend in the restaurant, which also may be a proxy for the service quantity (they see it as a compensation of the waiters for the inefficient use of the table).

The gratuity size may also be affected by the size of the group dining together. The theory is not clear, see Azar (2007a) or Lynn (2006). Customers in bigger groups may tip more because of the stronger social pressure, or can tip less because the customers' responsibility is more diffused in a bigger group. Moreover, it is easier for the waiting staff to wait to a group than individuals seated separately. Also, if customers pay together in the group, the magnitude effect can lower the percentage gratuity. The empirical results are unclear too. Freeman et al. (1975) and Bodvarsson and Gibson (1997) found out that the gratuity size decreases with the group size. Lynn and Grassman (1990) and Azar (2010b) found no relationship. Lynn and Latané (1984) found a lower gratuity in larger groups in one study and no effect in the other one. However, Conlin, Lynn, and O'Donoghue (2003) found out that the customers tip more when in bigger groups.

Gratuity size can also be affected by factors such as the customers' or waiters' gender, ethnicity, religiosity, political affiliation, and age. Although there is no economic theory predicting that these factors would influence the gratuity size, several researchers found the influence to be statistically significant. Hornik (1992) found out that female customers tip more than male customers, and waitresses get more than waiters. Conlin, Lynn, and O'Donoghue (2003) discovered that female customers tip more to waiters but other interactions are statistically insignificant. Azar (2010b) found out that female customers tip more than male customers. Lynn, Jabbour, and Kim (2012) found out that female customers tip on average less than male customers and also tip less sensitively to the service quality. Conlin, Lynn, and O'Donoghue (2003) found out that older customers tip less. Lynn, Jabbour, and Kim (2012) discovered that older customers tip less but more sensitively to the poor service than the younger ones. The difference among races and the impact of religiosity and political affiliation are not relevant for this study; an interested reader can find a good summary in Lynn (2006).

Several studies have shown that the waiting staff can influence the gratuity size by being friendly and using various psychological tricks that enhance a feeling of interpersonal connection of the customer with the server. Most studies found that friendlier waiting staff raise a higher gratuity, see e.g. Lynn and Simons (2000), Conlin, 
Lynn, and O'Donoghue (2003), and Azar (2010b). The feeling of friendliness and interpersonal connection can be successfully mimicked by the waiting staff. Lynn (2006) summarizes some of these practices (usually tested in field experiments). For instance, Hornik (1992) found out that customers tip more if the waiter/waitress touches them (the female customers react more), Strohmetz et al. (2002) found that customers tip more if they are given a small piece of chocolate when delivered a bill, etc.

Some studies also discovered that the gratuity size is affected by factors that are out of control of the waiting staff. Conlin, Lynn, and O'Donoghue (2003) found that the gratuity size increases with the quality of the meal (as rated by the customers). The gratuity size is also higher if customers order alcoholic beverages (Conlin, Lynn, and O'Donoghue, 2003, Azar, 2010b, and Lynn, Jabbour, and Kim, 2012) or desserts (Lynn, Jabbour, and Kim, 2012). However, Lynn and Grassman (1990) found out that gratuity was not related to alcohol consumption or food quality in their study. Lynn and Latané (1984) and Strohmetz et al. (2002) found that the gratuity is higher when the customers pay by card. Also, a physical attractiveness of waitresses affect the gratuity raised (Lynn and Simons, 2000, and Lynn, 2009). Surprisingly, even the current or expected future weather conditions can influence the gratuity size, see Rind and Strohmetz (2001) and papers quoted there.

There are only few studies (all by Lynn and his coauthors) that explore how cultural differences affect tipping norms among nations. The typical approach is to test how Hofstede's value dimensions (power distance, uncertainty avoidance, individualism, and masculinity) affect the number of industries where workers are tipped. The only study relevant for our paper is that by Lynn and Lynn (2004). They explore how much are waiting staff and taxi drivers tipped in various nations based on the nations' Hofstede's value dimensions. They show that uncertainty avoidance and masculinity raises the restaurant gratuity size while power distance and individualism do not influence it. However, they use only data on tipping from tourist guides and do not explore other determinants of the gratuity size. Their study does not include the Czech Republic.

\section{Data}

In order to analyze the tipping behavior in the Czech Republic, we collected 804 observations on restaurant tipping. The data gathering procedure was similar to the method used by Lynn and Latané (1984) in their second study and by Lynn and Simons (2000). The data were collected by observing the customers' behavior in four restaurants. A part of the data was recorded by cooperating waiting staff, the rest by one of the authors. This procedure has some advantages: 1) it allowed us to obtain much higher number of observations than typical studies in this area, which seems to be crucial for an initial study in a new country; 2) it avoided selection bias (some customers may avoid a survey, especially those giving a low gratuity or paying a large bill) and customers' cheating (customers may lie about the gratuity they gave, especially if the gratuity was low); and 3) the regular patrons were identified unambiguously, and we did not need to make any ad hoc assumption on how frequent visits constitute a regular patron-we simply asked the waiting staff to mark the customers they were able to recognize. Our procedure has also some drawbacks: we were neither able to ask the customers how they rated the service quality provided by the waiters, nor obtain the 
customers' socio-economic data including their incomes. However, we were able to measure a part of the service quality, namely attentiveness of the waiting staff. We measured it as a number of times a waiter approached the customers on their own initiative without being prompted by the customers or carrying them food or drink.

Each observation in our data set consists of the gratuity size in CZK, the bill size in $\mathrm{CZK}$, whether the payer was a regular patron of the restaurant, the size of the group sitting at the same table, the number of payers in the group, the customer's gender, gender of the waiting staff, the payment method used (either a debit or credit card, or cash), whether the customer was a foreigner ${ }^{4}$, whether anyone in the group ordered a lunch special ${ }^{5}$, whether anyone in the group consumed alcoholic beverages, whether anyone in the group smoked, the time the group spent in the restaurant, attentiveness of the waiting staff (as defined above), and some data on the current weather conditions (whether the sun was shining, whether it was raining or snowing, and the outside temperature). The gratuity size, the bill size, and the dummy variables for the patronage frequency and lunch specials were recorded by cooperating waiting staff, the weather conditions were downloaded from a meteorological web site, and the rest variables were recorded by one of the authors.

The data were collected in four restaurants in Brno ${ }^{6}$ since January to March, 2013. We attempted to gather roughly the same number of observations in every restaurant and on every day of week but weekends are somewhat underrepresented in our data set. Majority of observations were gathered since 7 p.m. on but about $15 \%$ of the observations were gathered earlier in the morning or the afternoon.

The restaurants were selected so that they represented typical inexpensive restaurants in Brno. Restaurant A was the only restaurant in our sample that is located in the downtown. It had 105 seats and was divided into a smoking section and a non-smoking area. It served hot food (its average price was about CZK 98) and also lunch specials. It was quite popular and its customers often needed to reserve their seats in advance. It was the only restaurant in our sample that allowed its customers paying by card. Restaurant B had 68 seats divided between a smoking section and a non-smoking area. It served hot food (its average price was about CZK 123) and also lunch specials. A reservation was needed less often. The restaurant was closed on Sundays. Restaurant C had capacity of 40 seats and smoking was allowed in the whole place. It did serve neither hot food, nor lunch specials. It was open since afternoons. Reservations were not needed. Restaurant D had 62 seats divided into a smoking section and a non-smoking

\footnotetext{
${ }^{4}$ We defined foreigners as people who did not speak the Czech or Slovak language. The Slovaks were not counted as foreigners because the two nations have very similar language and culture, were until recently part of one country, and there are many Slovaks living in the Czech Republic. ${ }^{5}$ Most Czech restaurants serve not only their standard menu around the noon but also lunch specials. These are usually two to four meals prepared in advance in a high quantity and offered at discount.

${ }^{6}$ Brno is the second largest city in the Czech Republic.
} 
area. It served only a limited number of simple hot meals (their average price was about CZK 78) and no lunch specials. It was open since afternoons.

\section{Results}

The average gratuity is CZK 10.1 or about $7.1 \%$ of the bill in our data set, the median gratuity is CZK 8, or $5.8 \%$ of the bill. Thus the Czech restaurant gratuity is much lower than the tipping norm known from the USA, Canada, or Israel. The number of customers that stiffed (i.e. left no gratuity at all) is 61 or $7.6 \%$ of 804 customers), i.e. somewhat higher than is usual in these three countries too. The whole distribution of the gratuity is presented in Figure 1.

Figure 1 Empirical distribution of gratuity in the data sample.
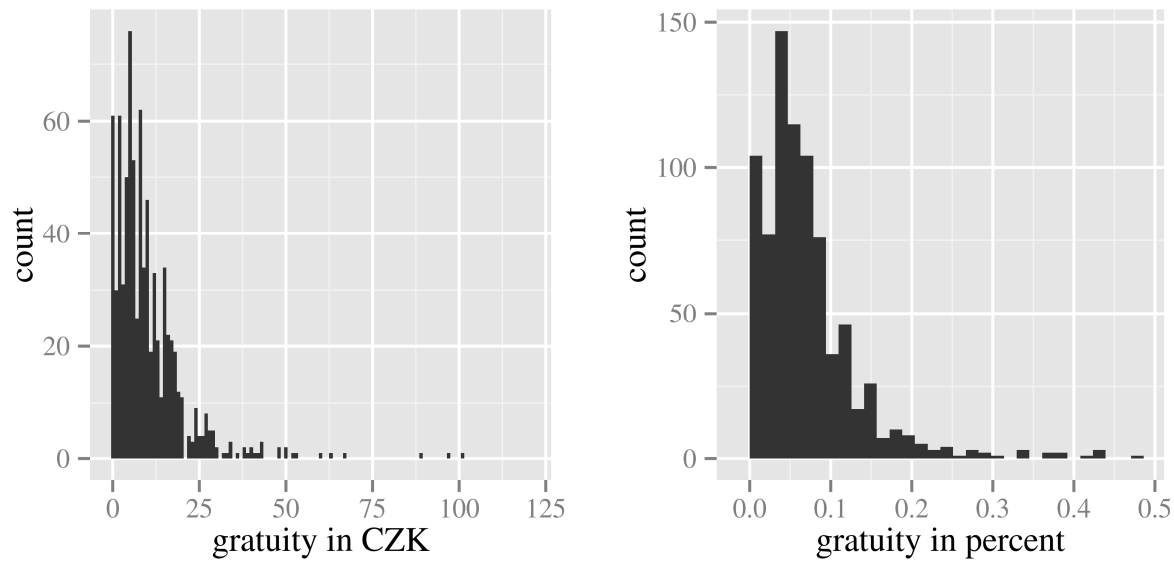

Besides the fact that the percentage gratuity is lower in the Czech restaurants, there is also a difference in rounding. A large proportion of customers round their gratuities to whole dollars in the USA, see Lynn, Jabbour, and Kim (2012). In contrast, the Czech customers do not round the gratuity but they use the gratuity to round their total expenditure (i.e. the sum of their bill and gratuity) up to the tens of CZK. ${ }^{7}$ This seems to be a relic of the way the gratuity originated in the Czech Republic: under the communist regime before 1989 and perhaps even earlier, the waiting staff were offered "to keep the change." In our data sample, $84.8 \%$ of total expenditures are rounded up to the tens of CZK. At the same time, only $15.5 \%$ of all tips are rounded this way. The percentage of the rounded tips is even lower when we exclude zero tips: only $8.6 \%$ of all non-zero

\footnotetext{
${ }^{7}$ The total expenditure need not to be rounded up to the nearest greater tens. We define as rounded such total expenditure that modulo 10 is equal to zero.
} 
tips are rounded. Moreover, $93.8 \%$ of the non-zero rounded tips are associated with the rounded bill, and hence it is not certain whether these customers wanted to round the tip or the total expenditure. Only $0.6 \%$ of the non-zero tips associated with a non-rounded bill are rounded up.

The Czech habit of rounding of the total expenditure means that we can expect to find a positive intercept of CZK 4.50 when regressing the gratuity on the bill size. The intercept of CZK 4.50 is the average amount of money needed to round the bill up to the nearest tens of $\mathrm{CZK}$, i.e. the average of $\mathrm{CZK} 0,1, \ldots, 9$ (there is no smaller coin than CZK 1 in the Czech Republic). The real question is whether or not gratuity depends on the bill size in the Czech restaurants, and how the relationship, if existing, is modified by other covariates.

To answer the question, we ran several regressions summarized in Table 1. All regression models are linear in parameters and use the gratuity in CZK rather than the gratuity as percentage of the bill size as the dependent variable. It is because of the expected positive intercept in CZK. If we used the gratuity as percentage of the bill as the dependent variable, we might get a spurious result that the percentage gratuity decreases in the bill size, see Lynn, Jabbour, and Kim (2012). Since the share of zero gratuities is low in our data set, we estimated the model parameters with OLS (as is usual in the literature). We report robust standard errors (HC3) because all regression models in Table 1 are heteroskedastic.

The regression models (1) and (2) test the relationship between the gratuity size and the bill size, the customers' patronage frequency and attentiveness of the waiting staff. Since the restaurants in our data sample were very diverse, we had to control for the differences among them. However, we found out that customers tipped significantly more only in restaurant $\mathrm{A}$, and the other three restaurants were not significantly different from each other. We therefore added only a dummy variable for the restaurant A. Both model (1) and (2) show that the expected gratuity in CZK rises with the bill size. We also tested whether the relationship is linear by adding a squared value of the bill size (the regression model is not reported here) but the parameter was never statistically significant. Thus we can conclude that the gratuity indeed rises with the bill size, and it rises roughly linearly.

The only difference between regression models (1) and (2) is in the way the rest covariates were added to the model. In model (1), they modify the intercept; in model (2), they modify the slope of the relationship between the gratuity and the bill size. Model (2) fits the data better and is also better in line with the "thinking in relative terms" hypothesis (Lynn, Jabbour, and Kim, 2012) that people tip in dollar terms but want to keep things in right proportions. Moreover, majority of the previous studies add the covariates in the way in which they change the marginal impact of the bill size. We therefore use model (2) as a basis for subsequent regression models.

Regression model (2) shows that attentiveness of waiting staff raises the gratuity: each time a waiter or waitress approaches the table on his/her own initiative, the expected gratuity rises by about half a percent of the bill size. This may be seen as a piece of evidence that gratuity is positively affected by the service quality in Czech restaurants. The impact per payer is rather weak: if a waiter/waitress raises his attentiveness by 
interquartile range, his gratuity rises by $1.4 \%$ of the bill, which is about CZK 1.82 for the medium-sized bill and CZK 2.93 for the third-quartile bill. However, the median number of payers at a table was 3, and hence the impact on the waiters' income from the increased attentiveness to a median group would be CZK 5.46 or CZK 8.79 respectively, and would be even higher for the larger groups, which is similar to the result of Conlin, Lynn, and O'Donoghue (2003). It may or may not motivate the waiting staff to offer a good service, and their motivation may be positively related to the group size. However, since we measured only one dimension of the service quality, the result should be seen as tentative-it is still possible that the Czech customers' sensitivity to the service quality is sufficiently high to compel a good service in all cases.

Table 1 Regression results. The dependent variable is the gratuity in CZK. Robust standard errors are reported.

\begin{tabular}{|c|c|c|c|c|c|}
\hline & (1) & (2) & (3) & (4) & (5) \\
\hline bill & $0.042^{* * *}(0.005)$ & $0.019^{* *}(0.009)$ & $0.023^{* *}(0.009)$ & $0.026^{* * *}(0.010)$ & $0.026^{* \star *}(0.010)$ \\
\hline patron & $-1.681^{* \star}(0.662)$ & & & & \\
\hline attentiveness & $0.609^{* * *}(0.128)$ & & & & \\
\hline restaurant $\mathrm{A}$ & $2.223^{* * *}(0.782)$ & & & & \\
\hline bill * patron & & $-0.012^{*}(0.006)$ & $-0.010^{* *}(0.005)$ & $-0.011^{* *}(0.005)$ & $-0.012^{* *}(0.005)$ \\
\hline bill * attentiveness & & $0.004^{* * *}(0.001)$ & $0.005^{* * *}(0.001)$ & $0.005^{* * *}(0.002)$ & $0.005^{* * *}(0.001)$ \\
\hline bill * restaurant $A$ & & $0.020^{* *}(0.008)$ & $0.014^{* *}(0.007)$ & $0.014^{*}(0.008)$ & $0.013^{*}(0.008)$ \\
\hline bill * group size & & & $-0.005^{* * *}(0.001)$ & $-0.004^{* * *}(0.001)$ & $-0.005^{* * *}(0.001)$ \\
\hline bill * payer=male & & & $0.014^{* * *}(0.004)$ & $0.014^{\star \star \star}(0.004)$ & $0.015^{\star \star \star}(0.004)$ \\
\hline bill * waiter=male & & & $-0.013^{* * *}(0.004)$ & $-0.012^{* * *}(0.004)$ & $-0.012^{* * *}(0.004)$ \\
\hline bill * lunch special & & & $-0.029^{* * *}(0.007)$ & $-0.031^{* * *}(0.008)$ & $-0.032^{* * *}(0.008)$ \\
\hline bill * foreigner & & & & $0.002(0.009)$ & \\
\hline bill * time at table & & & & $-0.002(0.002)$ & \\
\hline bill * alcohol & & & & $-0.002(0.007)$ & \\
\hline bill * smokers & & & & $0.005(0.006)$ & \\
\hline bill * card pmt. & & & & $-0.002(0.009)$ & \\
\hline bill * snowing & & & & & $-0.015^{* *}(0.006)$ \\
\hline bill * sunny & & & & & $-0.0004(0.005)$ \\
\hline bill * rainy & & & & & $0.001(0.006)$ \\
\hline bill * temperature & & & & & $-0.001(0.001)$ \\
\hline intercept & $0.405(1.282)$ & $3.781^{* * *}(0.686)$ & $4.480^{* * *}(0.622)$ & $4.480^{\star \star \star}(0.722)$ & $4.643^{\star * \star}(0.644)$ \\
\hline Observations & 804 & 804 & 804 & 804 & 804 \\
\hline$R^{2}$ & 0.442 & 0.483 & 0.539 & 0.542 & 0.549 \\
\hline Adjusted $R^{2}$ & 0.440 & 0.480 & 0.534 & 0.535 & 0.542 \\
\hline
\end{tabular}

Model (2) also shows that gratuity is lowered by patronage frequency: the regular patrons tip by $1.2 \%$ of the bill less than other customers. They also more often stiff 
(9.7\% of the regular patrons stiffed while only $5.6 \%$ of other customers did so). This result is rather surprising - all previous studies found either no relationship or a positive relationship (which would be in line with the economic theory). One explanation of this striking result may be that in fact there is no relationship between the patronage frequency and the gratuity size, and the relationship found in some previous studies is a result of a missing covariate, see Azar (2010a). Thus regular patrons tip more or less than the occasional customers because they belong to a different social group, not because of any strategic reasons. The US and the Czech regular patrons behave differently because they have different social characteristics. Perhaps, it is the wealthier customers (which give higher gratuity) who visit restaurants regularly in the USA, while Czech regular patrons are people more sensitive to prices, i.e. they tip less generously). This conjecture is supported by the fact that regular patrons more often order lunch specials and spend less than the occasional customers in the Czech restaurants $(11.8 \%$ of patrons ordered a lunch special while only $2.4 \%$ of the occasional customers did so; the patrons spent on average CZK 155.9 while the occasional customers spent CZK175). It also seems that it is the less wealthy people who visit the restaurants more often in the Czech Republic - they "go for a beer" (beer is the cheapest beverage in Czech restaurants). (An alternative explanation would be that the waiting staff can remember the least generous customers better.)

These results hold true even if we control for numerous other covariates. Regression model (3) adds interactions between the bill size and the group size, the gender of the customers, the gender of the waiting staff, and a dummy variable for lunch specials. All the variables have statistically significant parameters. A rise in the group size lowers the percentage gratuity: one extra person at the table lowers the percentage gratuity by about a half percent of the bill size. This seems to be in line with the "diffusion-of-theresponsibility" hypothesis. At the same time, we can reject the hypothesis that the group size lowers the gratuity because of the gratuity rounding. It is because we control for the rounding explicitly with the intercept. (We replaced the group size with the number of individual payers at the table in an alternative regression specification not reported here. The results were qualitatively similar because the correlation between the group size and the number of payers at the table is 0.87 . However, the model with the group size fitted the data better.)

Model (3) also indicates that there are differences between genders: male customers tip more generously than female customers, and waitresses can acquire a higher income from tips than waiters. The latter corresponds to what was observed in the USA; the former, however, is the opposite of the usual findings there.

The tipping behavior also differs between the customers that ordered a lunch special and those ordering an ordinary meal or drink. The gratuity is lower if a customer orders a lunch special. We cannot reject the hypothesis that customers ordering a lunch special only round up the total expenditure to the nearest tens of CZK and do not increase the gratuity depending on the bill size (the $p$-value of the model restriction that the sum of the bill size parameter and the parameter for the interaction between the bill size and the lunch special is equal to zero is 0.54 ). However, this may not be the case. Customers ordering a lunch special perhaps only stiff more often: $28.6 \%$ of customers ordering a lunch special stiffed, while only $6.02 \%$ of other customers did so. This result is similar 
to the finding that customers tip less for lunch than for dinner in the USA (Lynn and Simons, 2000, and Lynn, Jabbour, and Kim, 2012). However, it is not the same-the definition of the lunch specials includes only selected meals offered at a discount, not all lunches.

The intercept is CZK 4.48 in model (3). We cannot reject the hypothesis that customers round the total expenditures upward to tens of CZK, and hence the true intercept is 4.5 ( $p$-value is 0.96). The correctly fitted intercept supports the notion that the structure of the model is more or less correct. The positive intercept also means there is a magnitude effect in the Czech restaurant tipping.

Regression model (4) controls for the time spent at the table, consumption of alcoholic beverages, smoking, payment method, and presence of foreigners at the table. None of these variables has a statistically significant parameter and their inclusion into model (3) does not improve the fit of the model ( $p$-value of the $F$-test is 0.28 ). All the former parameters stay almost the same.

The statistical insignificance of the parameter for the payments with the debit or credit card may be caused by the small number of observations (30 or $3.7 \%$ of 804 ) in our data set, where customers paid by card. However, the parameter has the opposite sign than the parameter estimated in the USA: in the Czech Republic, the use of a card (insignificantly) lowers the gratuity. It may be because the card user stiff more often ( $13.3 \%$ of card users stiffed while only $7.4 \%$ of cash users did so). This may be caused by the Czech custom to round the total expenditure up: customers may not be able to ask the waiter to "keep the change" in Czech restaurants when they pay by card-either because the restaurant does not allow it, or because the customers do not know how to do it.

Regression model (5) controls for weather conditions. Only snowfall has a significant impact on the gratuity size. Even though the inclusion of these variables improves the fit of model (3) ( $p$-value of the $F$-test is 0.001$)$, the former parameters are not affected.

In general, the Czech tipping norm is much weaker than the norms known in the USA, Canada, and Israel, and hence there is greater randomness (i.e. the unexplained variability) in the gratuity data here. The bill size alone explains about $40 \%$ of the variability of gratuity in CZK (the $R^{2}$ of the model where the bill size is the only explanatory variable is $40.4 \%$ ), and model (3) explains about one half of the variability (its $R^{2}$ is about $53.9 \%$ ). In contrast, Lynn (2006) claims that the bill size alone explains about $69 \%$ of the gratuity size variability in the USA, and typical models of the dollar gratuity explain about three quarters of the variability of the data.

\section{Conclusions}

Our study shows that in the Czech Republic, restaurant tipping evolved into a form that has some features similar to the tipping norms known in the USA, Canada, and Israel, but there are also striking differences. As in the three countries, gratuity increases with the bill size in the Czech Republic. However, the gratuity as a percentage of the bill is much lower here than in the USA, Canada, or Israel, and so is also the marginal impact of the bill on the gratuity size. The bill size explains here a lower part of the gratuity 
variability too, i.e. the Czech tipping norm is weaker than the norms in the three countries. In the same way, the service quality raises a more generous gratuity in the Czech Republic but the increase seems to be small and it is uncertain whether it can compel a good service. However, the strength of the motivation increases with the group size.

The most striking difference between the Czech Republic and the three countries is in behavior of regular patrons. While in the USA, Canada, and Israel, regular patrons tip the same or higher percentage than the occasional customers, their Czech counterparts tip significantly less and they stiff more often. This supports the hypothesis that the relationship between the customer frequency and the gratuity size is an artifact of a missing variable, and the regular patrons tip differently because they belong to a different social group than occasional customers. The second most important difference is in the behavior of the customers that pay by card. While they tip more generously in the USA, they stiff more often in the Czech Republic, and the interaction between the bill size and the card use is statistically insignificant.

Many factors modifying the relationship between the gratuity and the bill size are the same as in the three countries but the parameter signs are sometimes opposite. First, the group size lowers the percentage gratuity, which supports the diffusion of the responsibility hypothesis. Second, there are differences between genders too: male customers tip more than female customers, and waitresses earn more than their male colleagues. The latter result corresponds to what is usually observed in the USA, the former one is the opposite to the usual findings there. Third, similar to most studies, the time spent at the table does not change the gratuity size. Fourth, consumption of the alcoholic beverages does not change the gratuity in the Czech restaurants (some US studies found some impact, others did not). Fifth, there is the magnitude effect due to the positive intercept. Sixth, the gratuity may be affected by weather.

There are also some factors specific to the Czech Republic. First, customers tip less and stiff more often when they order a lunch special. Second, Czech customers round the total expenditures, not the gratuities. This creates the positive intercept when regressing the gratuity in CZK on its covariates, and hence the magnitude effect.

There is still a space for a further research of the tipping behavior in the Czech Republic because of the limitations of the present paper given by the data collection procedure. We collected data in inexpensive restaurants and were not able to gather both the customer's socio-economic data (especially their incomes) and their service quality assessment. Thus our results of the service quality influence on the gratuity are only tentative. Possible future studies can focus on customers' sensitivity to the service quality and explore whether it is sufficient to compel a good service. Second, future studies can explore whether the impact of the patronage frequency remains when controlled for the customers' income and other socio-economic data and when data are collected in expensive restaurants, too. Third, it would be also interesting to replicate the present study after several years to learn whether the Czech tipping norm gets more refined over the time (i.e. the explained part of the gratuity variance rises in time), and whether it converges further to the norm known from abroad. 


\section{References}

AZAR, O. H. (2007a). The Social Norm of Tipping: A Review. Journal of Applied Social Psychology. 37(2), pp. 380-402.

AZAR, O. H. (2007b). Do People Tip Strategically, to Improve Future Service? Theory and Evidence. Canadian Journal of Economics/Revue Canadienne d'économique. 40(2), pp. 515-27.

AZAR, O. H. (2009). Incentives and Service Quality in the Restaurant Industry: The Tipping-service Puzzle. Applied Economics. 41(15), pp. 1917-27.

AZAR, O. H. (2010a). Tipping Motivations and Behavior in the US and Israel. Journal of Applied Social Psychology. 40(2), pp. 421-57.

AZAR, O. H. (2010b). Do People Tip Because of Psychological or Strategic Motivations? An Empirical Analysis of Restaurant Tipping. Applied Economics. 42(23), pp. 3039-44.

BODVARSSON, Ö. B., and GIBSON, W. A. (1994). Gratuities and Customer Appraisal of Service: Evidence from Minnesota Restaurants. The Journal of SocioEconomics. 23(3), pp. 287-302.

BODVARSSON, Ö. B., and GIBSON, W. A. (1997). Economics and Restaurant Gratuities: Determining Tip Rates. American Journal of Economics and Sociology. 56(2), pp. 187-203.

BODVARSSON, Ö. B., and GIBSON, W. A. (1999). An Economic Approach to Tips and Service Quality: Results of a Survey. The Social Science Journal. 36(1), pp. 137-47.

BODVARSSON, Ö. B., LUKSETICH, W. A., and MCDERMOTT, S. (2003). Why Do Diners Tip: Rule-of-Thumb or Valuation of Service? Applied Economics. 35(15), pp. 1659-65.

CONLIN, M., LYNN, M., and O'DONOGHUE, T. (2003). The Norm of Restaurant Tipping. Journal of Economic Behavior \& Organization. 52(3), pp. 297-321.

FREEMAN, S., WALKER, M. R., BORDEN, R., and LATANÉ, B. (1975). Diffusion of Responsibility and Restaurant Tipping: Cheaper by the Bunch. Personality and Social Psychology Bulletin. 1(4), pp. 584-87.

GREEN, L., MYERSON, J., and SCHNEIDER, R. (2003). Is There a Magnitude Effect in Tipping? Psychonomic Bulletin \& Review. 10(2), pp. 381-86.

HARRIS, M. B. (1995). Waiters, Customers, and Service: Some Tips About Tipping. Journal of Applied Social Psychology. 25(8), pp. 725-44.

HORNIK, J. (1992). Tactile Stimulation and Consumer Response. Journal of Consumer Research. 19(3), pp. 449-58.

KAHNEMAN, D., KNETSCH, J. L., and THALER, R. (1986). Fairness as a Constraint on Profit Seeking: Entitlements in the Market. The American Economic Review. 76(4), pp. 728-41. 
LYNN, M. (2003). Restaurant Tips and Service Quality: A Weak Relationship or Just Weak Measurement. International Journal of Hospitality Management. 22(3), pp. 32125 .

LYNN, M. (2006). Tipping in Restaurants and Around the Globe: An Interdisciplinary Review. In Handbook of Contemporary Behavioral Economics: Foundations and Developments, edited by M. Altman, pp. 626-43. M. E. Sharpe Publishers.

LYNN, M. (2009). Determinants and Consequences of Female Attractiveness and Sexiness: Realistic Tests with Restaurant Waitresses. Archives of Sexual Behavior. 38(5), pp. 737-45.

LYNN, M., and GRASSMAN, A. (1990). Restaurant Tipping: An Examination of Three 'Rational'explanations. Journal of Economic Psychology. 11(2), pp. 169-81.

LYNN, M., and LATANÉ, B. (1984). The Psychology of Restaurant Tipping. Journal of Applied Social Psychology. 14(6), pp. 549-61.

LYNN, M., and LYNN, A. (2004). National Values and Tipping Customs: A Replication and Extension. Journal of Hospitality \& Tourism Research. 28(3), pp. 35664.

LYNN, M., and MCCALL, M. (2000). Gratitude and Gratuity: A Meta-Analysis of Research on the Service-Tipping Relationship. The Journal of Socio-Economics. 29(2), pp. 203-14.

LYNN, M., and SIMONS, T. (2000). Predictors of Male and Female Servers' Average Tip Earnings1. Journal of Applied Social Psychology. 30(2), pp. 241-52.

LYNN, M., and STURMAN, M. C. (2003). It's Simpler Than It Seems: An Alternative Explanation for the Magnitude Effect in Tipping. International Journal of Hospitality Management. 22(1), pp. 103-10.

LYNN, M., JABBOUR, P., and KIM, W. G. (2012). Who Uses Tips as a Reward for Service and When? An Examination of Potential Moderators of the Service-tipping Relationship. Journal of Economic Psychology. 33(1), pp. 90-103.

RIND, B., and STROHMETZ, D. (2001). Effect of Beliefs About Future Weather Conditions on Restaurant Tipping. Journal of Applied Social Psychology. 31(10), pp. 2160-64.

ROGElBERG, S. G., PlOYHART, R. E., BALZER, W. K., and YONKER, R. D. (1999). Using Policy Capturing to Examine Tipping Decisions. Journal of Applied Social Psychology. 29(12), pp. 2567-90.

STROHMETZ, D. B., RIND, B., FISHER, R., and LYNN, M. (2002). Sweetening the Till: The Use of Candy to Increase Restaurant Tipping. Journal of Applied Social Psychology. 32(2), pp. 300-309. 